\title{
RITMOS DA DINÂMICA FLUVIAL NEO-CENOZÓICA CONTROLADOS POR SOERGUIMENTO REGIONAL E FALHAMENTO: O VALE DO RIO DAS VELHAS NA REGIÃO DE BELO HORIZONTE, MINAS GERAIS, BRASIL
}

\author{
Antônio Magalhães Jr.* \& Allaoua Saadi**
}

\begin{abstract}
The study of fluvial dynamics of the Rio das Velhas in the section connecting the Quadrilátero Ferrífero and the Bambuí basin, relying on a compilation of geomorphological, sedimentological and structural data indicates a Cenozoic morphogenesis controlled by uplift of regional scale with interference of faults located at the contacts of morphostructural compartments. These compartments are strongly adapted to the Precambrian litostructural domains controlling the geomorphological configuration of the different parts of the river valley.

The initial chronological datum is marked by remainders of the Sulamericana Surface (Neogene). During the Plio-Pleistocene period three levels of stepped terraces were formed. During the Holocene a inner floodplain developed in the Lower Terrace.

The level of the Upper Terrace (Pliocene) corresponds to the end of dissection phase which reaches a depth of $150 \mathrm{~m}$ and shows a equilibrated longitudinal profile over the whole area. The sediments of the Middle and Lower Terraces have been deposited after new dissection phases with minimum depths of 60 and $10 \mathrm{~m}$, respectively. These data of dissections depths and the stamped position of the floodplain confirms the gradual decreasing of the regional uplift intensity during the Pleistocene times.

The last three events of the valley formation indicate a superimposition of the Rio das Velhas onto the structures of the Quadrilátero Ferrífero with formation of a water-gap at the passage of the Serra do curral, named "Fecho de Sabará". In consequence occurs a strong local retention of alluvial sediments causing a important alteration of river dynamics.

The decreasing uplift during Holocene times is accompanied by the transition from braided channels systems, prevailing during the Pleistocene, to a meandering channel type. The effects of historic mining activity induce the return to the braided system.

Tectonic activity by faulting is demonstrated by dislocations in the alluvial sequences of the Lower Terrace and in the longitudinal profile of the Middle and Upper Terraces with a total off-set of $50 \mathrm{~m}$ as well as by river capture younger than the Middle Terrace.

Palavras-chave: Morfodinâmica fluvial, Controle Tectônico, Superimposição, Rio das Velhas.
\end{abstract}

\section{INTRODUÇÃO}

O rio das Velhas, afluente de margem esquerda do rio São Francisco, nasce no limite sul do Quadrilátero Ferrífero, o qual atravessa por inteiro em direção NNW. O trecho estudado (alto-médio vale), localizado na região de Belo Horizonte, entre a cidade de Sabará e a vila de Pinhões (Município de Lagoa Santa), inicia-se pela travessia em garganta da borda norte do Quadrilátero Ferrífero. Esta garganta foi aqui denominada de "Fecho de Sabará", por analogia à feição correspondente na travessia do rio Paraopeba, há muito tempo conhecida por "Fecho do Funil".

A borda norte do Quadrilátero Ferrífero é representada pela imponente escarpa da Serra do Curral, uma das mais significativas feições geomorfológicas regionais, que marca o contato entre um maciço antigo cujas estruturas foram modeladas por uma orogênese précambriana e uma bacia metassedimentar do Proterozóico Superior, instalada sobre o embasamento arqueano do Craton do São Francisco.

Muitas especulações de caráter geral têm sido feitas a respeito da evolução geomorfológica da região e, em especial, dessa zona de contato. No entanto, não se logrou até hoje abordar a questão através de trabalhos de detalhe, alicerçados no levantamento e análise de dados sistematizados.

Com o objetivo de suprir essa lacuna, idealizou-se um programa de investigações visando o estudo da evolução geomorfológica da região, baseado nas seguintes concepções:

a - as áreas de contato devem apresentar a maior riqueza de testemunhos paleo-geomorfológicos e, conseqüentemente, de informações;

b - em meio tropical, o estudo da dinâmica fluvial deve propiciar os melhores e mais fieis marcos fenomenológicos e cronológicos da evolução do relevo, na escala de tempo do Cenozóico.

Este trabalho objetiva conseqüentemente, em associação com pesquisas similares desenvolvidas em vários pontos da referida escarpa, em especial no trecho correspondente do vale do rio Paraopeba, fornecer uma contribuição ao entendimento da evolução da dinâmica fluvial cenozóica da área. 


\section{MÉTODO E TÉCNICAS UTILIZADOS}

A identificação dos terraços fluviais foi feita, numa primeira abordagem, por interpretação de aerofotos em escala de 1:25.000, sendo completada posteriormente por reconhecimento e caracterização no campo. Após lançamento das ocorrências em base topográfica, também em escala de 1:25.000, foram definidos os níveis cronológicos de terraceamento e suas relações em seções transversais e longitudinais ao vale.

Paralelamente, foram levantadas seções estratigráficas em todas as ocorrências de seqüências aluviais. Da análise destas resultou a definição de "seções-síntese" para cada um dos níveis de terraceamento.

A interpretação das litofácies recorrentes nas seções originais serviu de base à reconstituição dos padrões deposicionais correspondentes.

Como subsídio à investigação das variações espaciais na morfodinâmica fluvial, foram realizadas análises petrográficas e morfométricas em amostras de seixos e, quando necessário, em áreas de captura e/ou confluência, medidas de paleocorrentes. Para auxiliar a compreensão da evolução temporal e suas relações com as condições litológicas e estruturais do trecho de vale estudado, foram consideradas as variações ocorrendo ao longo do perfil longitudinal na altura dos níveis de terraço e espessura máxima das seqüências aluviais correspondentes.
O quadro preliminar da morfodinâmica cenozóica da área é o resultado do tratamento sintético dessas informações, no contexto espacial de uma segmentação do trecho de vale realizada em função de critérios morfoestruturais, sendo complementado por interpretações derivadas da análise de deformações neotectônicas observadas em seqüências aluviais.

\section{CONTEXTO GEOLÓGICO E GEOMORFOLÓGICO}

\section{Condições morfoestruturais regionais}

No trecho estudado, o vale do rio das Velhas percorre aproximadamente $35 \mathrm{~km}$ em linha reta, entre os municípios de Sabará, a sul, e Lagoa Santa, a norte (Fig. 1). Neste percurso, o rio atravessa três grandes unidades morfoestruturais regionais: Quadrilátero Ferrífero a sul, Depressão de Belo Horizonte na porção central, e Borda da Bacia do Grupo Bambuí a norte (Fig. 2).

O Quadrilátero Ferrífero é aproximadamente limitado pela ocorrência das rochas précambrianas do Supergrupo Minas na região, englobando quartzitos, conglomerados e filitos do Grupo Caraça, itabiritos e filitos do Grupo Itabira, e quartzitos, filitos, conglomerados e xistos do Grupo Piracicaba (Ladeira 1980). Juntamente com os quartzitos e conglomerados da Série Itacolomi, estas rochas foram depositadas

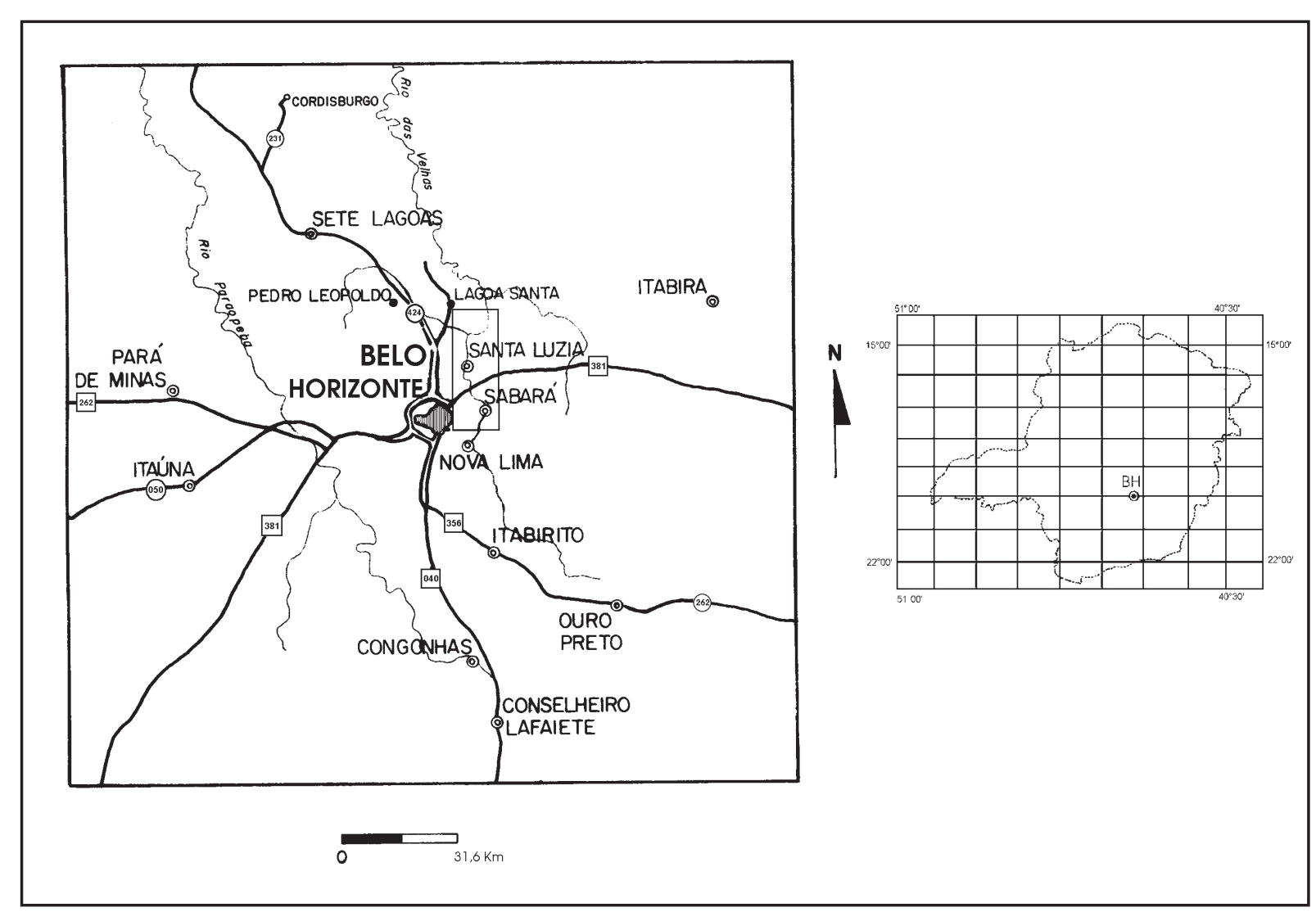

Figura 1: Localização da área (Fonte: Mapa Rodoviário de Minas Gerais. DNER, 1986).

Figure 1: Location of the area (After Road Map pf Minas Gerais. DNER, 1986). 


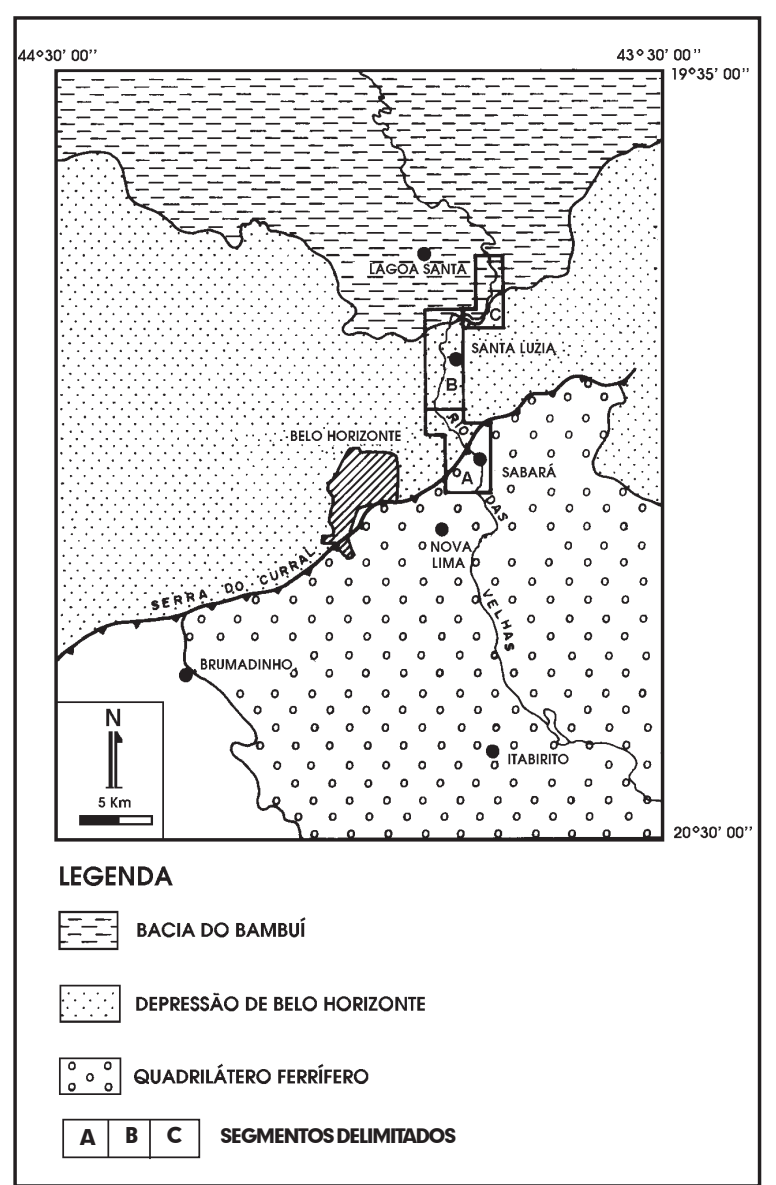

Figura 2: Localização da área com relação aos compartimentos morfoestruturais.

Figure 2: Location of the area related to the morphostructural compartments.

sobre uma seqüência arqueana tipo greenstone-belt, assentada diretamente sobre o embasamento granitognáissico: o Supergrupo Rio das Velhas, englobando xistos, filitos, quartzitos, dolomitos e conglomerados. As rochas apresentam-se geralmente muito deformadas como conseqüência de uma complexa evolução tectônica. O quadro atual configurou-se na fase orogenética pós-Itacolomi (Guild 1960, Dorr 1969, Moore 1969, Ladeira 1980).

Eventos tectono-sedimentares cenozóicos atribuidos ao período Oligoceno-Mioceno foram reconhecidos nas bacias do Gandarela e de Fonseca (Gorceix 1884) e do Gongo Soco (Saadi et al. 1992), constituídas de seqüências fluviais e lacustres.

A geomorfologia do Quadrilátero Ferrífero apresenta forte controle lito-estrutural e fortes contrastes de resistência litológica, refletindo-se em modelado de dissecação acentuada, importantes variações altitudinais e ocorrência de serras e cristas (Serras do Curral, do Caraça, de Ouro Branco, da Moeda) cortadas por vales epigênicos (rio das Velhas no Fecho de Sabará, rio Paraopeba no Fecho do Funil). A presença de remanescentes de várias superfícies de aplainamento foi destacada por King (1956), Dorr (1969) e Barbosa (1980), mas contestada por Varajão (1991), com base nas correlações detectadas entre os presumíveis pediplanos e as variações nas condições litoestruturais.

A confecção de perfís em varredura comprovou que a Serra do Curral e seu prolongamento NW (Serra de Sabará) é a unidade morfológica melhor diferenciada, em função do controle litológico exercido por itabiritos e quartzitos. Esta é suportada por uma estrutura monoclinal sob forma de hog-back, cuja vertente sul é a mais íngreme. O rio das Velhas a atravessa em corte epigênico (water-gap) no Fecho de Sabará, adentrando em seguida a Depressão de Belo Horizonte.

Nesta depressão afloram as rochas granitognáissicas do embasamento arqueano, do Cráton do São Francisco. As altitudes médias e a morfologia são então contrastantes com as do domínio anterior: cerca de 800 $m$ de altitude média e morfologia de colinas suavizadas.

Mais ao norte, próximo a Lagoa Santa, o rio das Velhas atravessa a borda sul da bacia metassedimentar do Grupo Bambuí (Proterozóico Superior). Segundo Dardenne (1978), o Grupo Bambuí constitui-se de conglomerados e filitos da Formação Jequitaí, calcários e dolomitos da Formação Sete Lagoas, folhelhos e siltitos da Formação Serra de Santa Helena, calcários e siltitos da Formação Lagoa do Jacaré, folhelhos e siltitos da Formação Serra da Saudade e siltitos e arcóseos da Formação Três Marias. Apesar destas rochas terem sido depositadas em grande parte sobre o Cráton do São Francisco, muitas estruturas aflorantes atestam a ocorrência de atividade tectônica posterior (Couto et al. 1983, Costa \& Grossi Sad 1987, Alkmin et al. 1989).Importante influência da neotectônica na evolução morfogenética da região foi definida por Saadi (1991, 1993), no contexto da tectônica recorrente fanerozóica.

A morfologia apresenta associação de suaves colinas alongadas e diversas formas cársticas refletindo a influência do substrato litológico. As altitudes médias locais permanecem em torno da cota $800 \mathrm{~m}$ como no domínio anterior, mas com início de um caimento topográfico contínuo em direção ao norte, ou seja rumo ao centro da bacia.

\section{Compartimentação do Vale do Rio das Velhas no trecho estudado}

A análise geomorfológica da área de estudo revelou a existência de importantes variações na morfologia do vale do rio das Velhas, o que permitiu a sua subdivisão em três segmentos (denominados A, B e C, de montante para jusante), cujos limites são praticamente coincidentes com os dos grandes compartimentos morfoestruturais (vide Fig. 2).

$\mathrm{Na}$ maior parte do segmento A, segmento meridional, a morfologia reflete os contrastes de resistência litológica do Quadrilátero Ferrífero. Predominam cristas e espigões com vertentes íngremes, geralmente talhadas na rocha sã ou cobertas por delgado manto coluvial. Os vales são estreitos e 
fortemente encaixados, com baixo grau de sinuosidade. O rio das Velhas apresenta bruscas mudanças de direção que evidenciam o forte controle estrutural.

No segmento B, associado à Depressão de Belo Horizonte, há notável mudança no comportamento geomorfológico em relação ao segmento de montante. No embasamento granito-gnáissico alterado, o vale do rio das Velhas torna-se aberto e sinuoso, limitado geralmente por baixas colinas de topos arredondados e vertentes suaves cobertas por espesso manto eluvial e, às vezes, coluvial.

O segmento $\mathrm{C}$, segmento setentrional, está associado à borda da Bacia do Bambuí. Este é morfologicamente caracterizado por interflúvios alongados com vertentes íngremes, geralmente cobertas por delgado manto eluvial. $\mathrm{O}$ vale apresenta-se aberto e sinuoso sobre substrato granito-gnáissico, passando a estreito e fortemente encaixado sobre substrato carbonático.

\section{SÍNTESE DOS RESULTADOS}

\section{Níveis deposicionais e sequências estratigráficas: descrição e interpretação}

Foram identificados 4 níveis deposicionais aluviais, sendo três situados em terraços escalonados (denominados Superior, Intermediário e Inferior, do mais antigo ao mais recente) e o quarto na várzea, esta sendo embutida no Terraço Inferior.

As ocorrências dos referidos pacotes aluviais foram mapeadas em todo o trecho estudado, na escala de 1:25.000. Os extratos de mapas representados pelas figuras 3, 4 e 5, ilustram a organização espacial dos mesmos nos trechos mais significativos, bem como a localização das seções transversais levantadas. Os perfís estratigráficos sintéticos relativos a cada um dos níveis deposicionais são apresentados na Fig. 6, no contexto da seção transversal ideal do vale no trecho estudado.

Os níveis de terraços apresentam recorrência cíclica

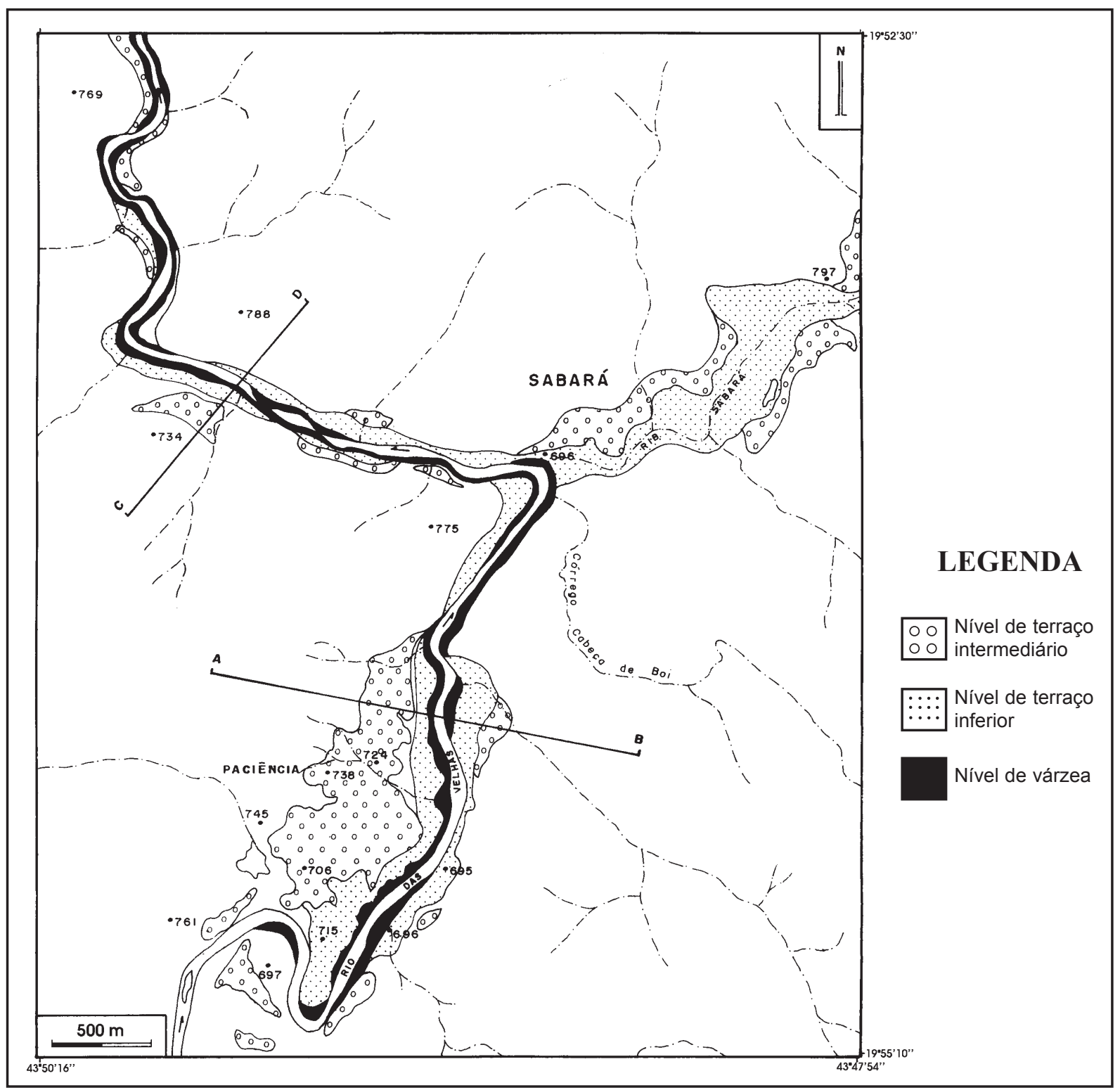

Figura 3: Mapa dos níveis deposicionais aluviais - Segmento A Figure 3: Map of the aluvial deposits - Segment A. 


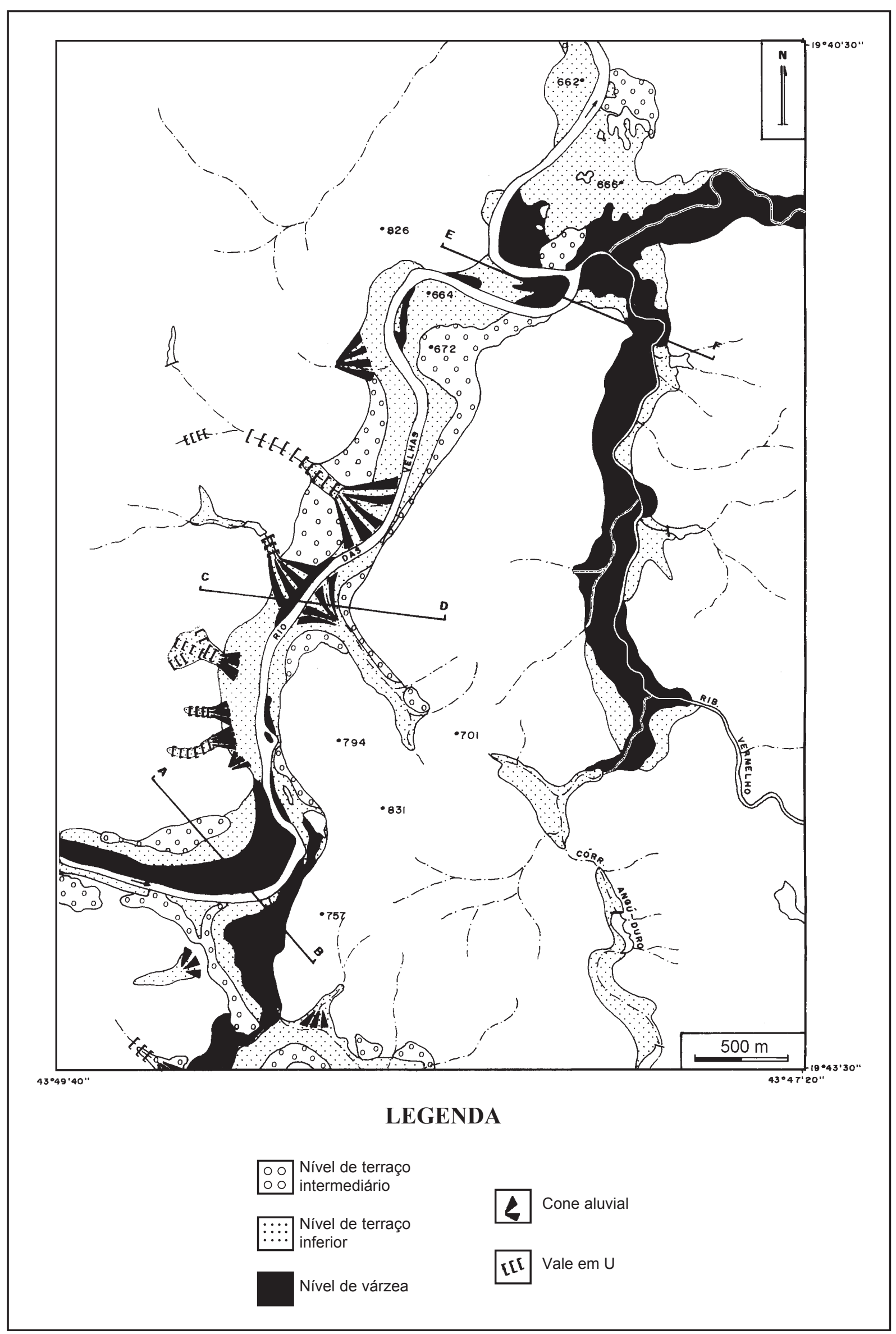

Figura 4: Mapa dos níveis deposicionais aluviais - Segmento B.

Figure 4: Map of the aluvial deposits - Segment B. 


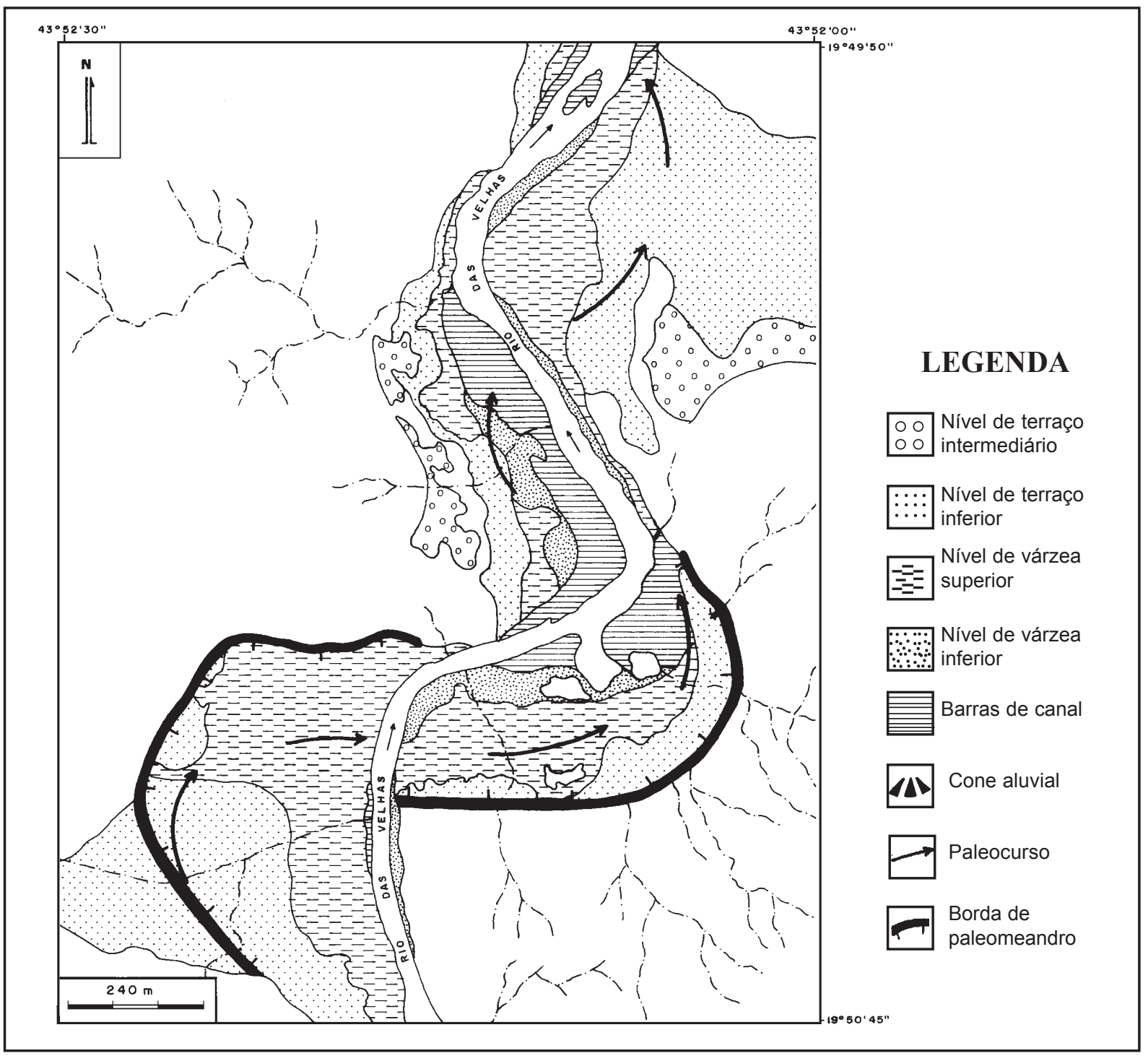

Figura 5: Mapa dos níveis deposicionais aluviais - Segmento C. Figure 5: Map of the aluvial deposits - Segment $C$.

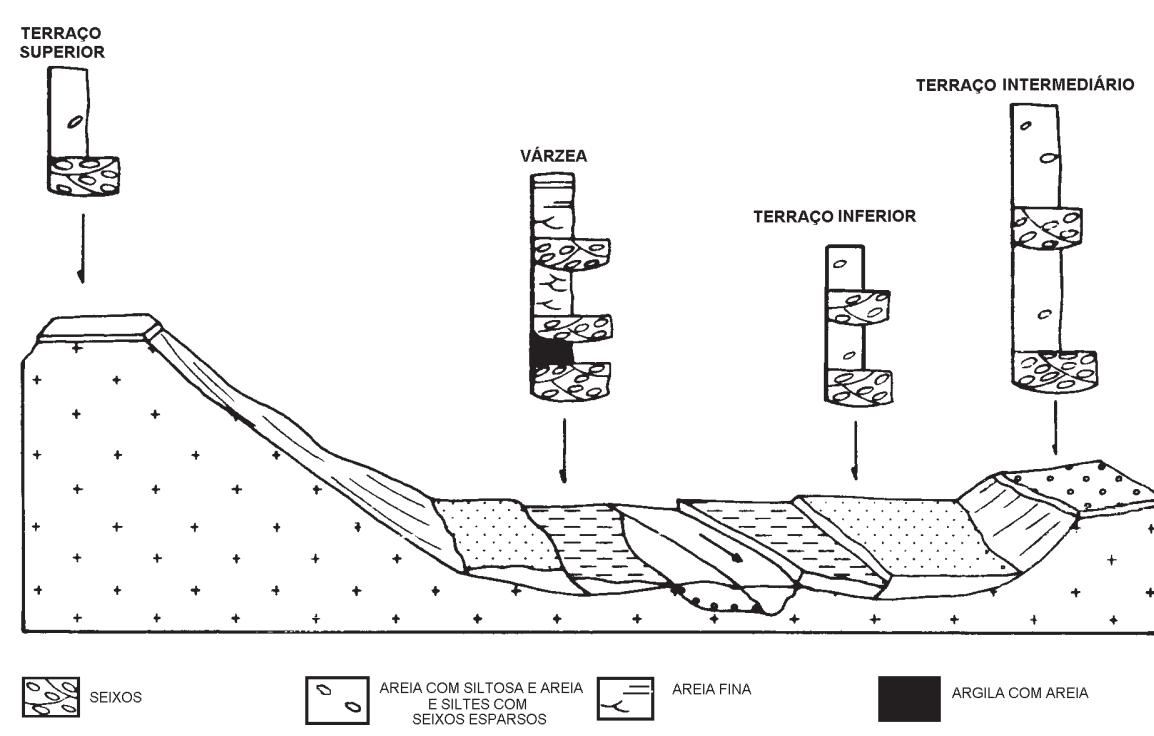

Figura 6: Seção transversal ideal e perfis estratigráficos sintéticos dos níveis de terraços. Figure 6: Valley cross section and resumed stratigraphic logs of the terrace levels. 
de cascalho suportado (pebble suported conglomerate com seixos de quartzo, quartzito e itabirito arredondados a subarredondados, em proporções variáveis), alternados com fácies areno-siltosa a siltoarenosa contendo seixos esparsos. A interpretação destas litofácies como associadas a ambiente de leito de canal e barras de canal respectivamente, permitiu a reconstituição de paleossistemas fluviais com padrão deposicional próximo ao entrelaçado, com abundante carga de leito.

No nível de várzea foram identificadas três fases deposicionais responsáveis por seqüências cíclicas de cascalho suportado na base (seixos de quartzo, quartzito e itabirito arredondados a subarredondados, tamanho médio de 2 a $3 \mathrm{~cm}$ ), recobertas por material arenoso a argilo-arenoso com relativa abundância de matéria orgânica (Fig. 7). Verificou-se gradual redução na presença de finos da primeira à terceira fase (mais antiga para mais recente). As referidas seqüências são respectivamente interpretadas como fácies de leito de canal (cascalho) e fácies de planície de inundação com meandros abandonados por chute cut-off e neck cutoff ocasionais (material mais fino). Desta forma, o padrão deposicional original apresenta-se de tipo próximo ao meandrante, ao contrário dos terraços. A reduzida espessura das seqüências (cerca de 1,5 m) e a presença ocasional de depósitos argilosos orgânicos não permitem propôr um padrão meandrante clássico.

\section{Variações longitudinais das propriedades estratigráficas nos níveis de terraços}

A análise das seqüências deposicionais dos níveis de terraços, ao longo do perfís longitudinais dos mesmos, permitiu a identificação de variações de algumas de suas propriedades, em associação com a

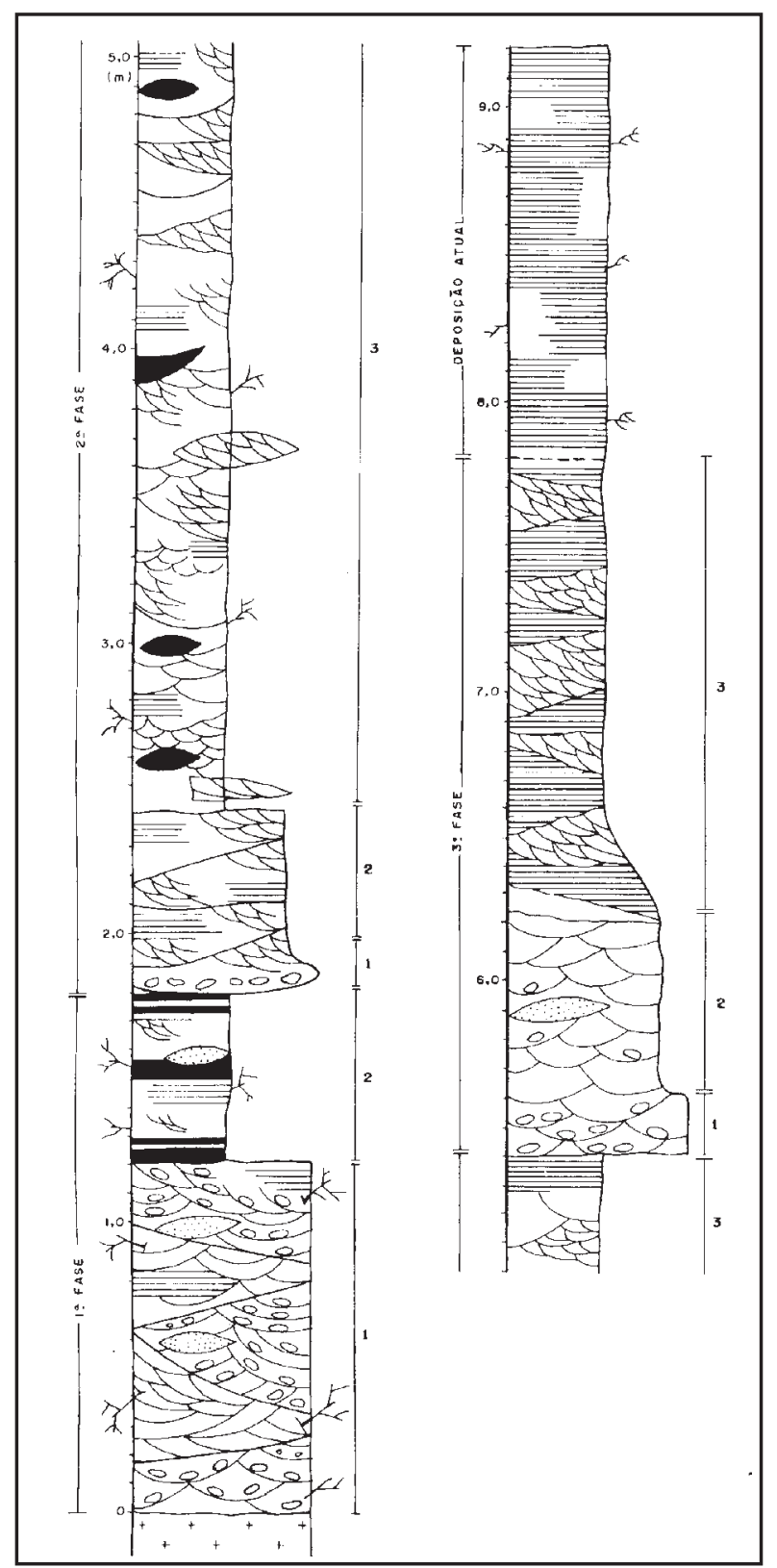

Figura 7: Perfil-síntese do nível de várzea.

Figure 7: Stratigraphic section of the floodplain. 
segmentação do vale (Fig. 8 e Quadro 1). Significativas variações na espessura das seqüências, comprimento médio e petrografia dos seixos (este último no caso dos terraços Intermediário e Inferior), confirmaram o condicionamento dos eventos deposicionais cenozóicos pela compartimentação morfoestrutural, conforme anteriormente proposto por Magalhães Jr. \& Saadi 1993.

\section{Evidências da atividade neotectônica}

A atividade da tectônica durante o desenvolvimento da dinâmica fluvial cenozóica é evidenciada por anomalias nos perfís longitudinais dos níveis de terraceamento, por deformações diretas nos terraços e, no segmento $\mathrm{C}$, pela ocorrência de uma captura fluvial na região de Pinhões.

As anomalias ocorrendo nos perfís longitudinais dos

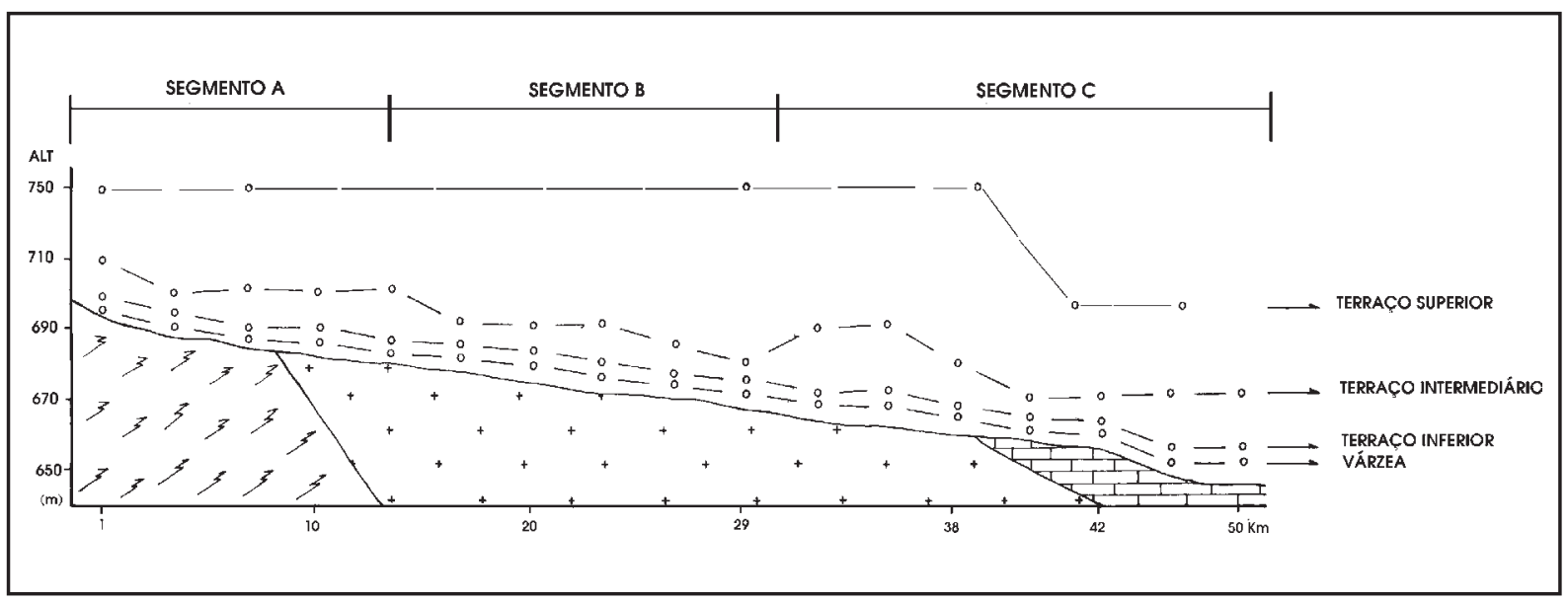

Figura 8: Distribuição longitudinal dos níveis deposicionais aluviais.

Figure 8: Longitudinal distribution of the aluvial levels.

Quadro 1: Propriedades das sequências deposicionais dos níveis de terraços

\begin{tabular}{|c|c|c|c|c|c|}
\hline $\begin{array}{l}\text { Terraçol } \\
\text { Segmento }\end{array}$ & & $\begin{array}{c}\text { Altural } \\
\text { Altitude da } \\
\text { base }(\mathrm{m})\end{array}$ & $\begin{array}{l}\text { Petrografia dos } \\
\text { seixos }\end{array}$ & $\begin{array}{l}\text { Comprimento } \\
\text { dos seixos } \\
\text { (cm) }\end{array}$ & $\begin{array}{l}\text { Espessura } \\
\text { Máxima } \\
\text { (m) }\end{array}$ \\
\hline Superior & & $\begin{array}{l}50 / \\
750\end{array}$ & quartzo, itabirito & 5 & 5 \\
\hline Superior & $B$ & $\begin{array}{l}70 / \\
750\end{array}$ & quartzo, itabirito & 5 & 5 \\
\hline Intermediário & & $\begin{array}{c}15 / \\
710-700\end{array}$ & $\begin{array}{ll}\text { itabirito } & 49 \% \\
\text { quartzo } & 41 \% \\
\text { quartzito } 10 \%\end{array}$ & 6 & $\begin{array}{c}\text { Montante da Serra do Curral: } 40 \\
\text { Jusante da Serra do Curral: } 10\end{array}$ \\
\hline Intermediário & $\mathrm{B}$ & $\begin{array}{c}15 / \\
690-680\end{array}$ & $\begin{array}{l}\text { quartzo } 60 \% \\
\text { itabirito } 35 \% \\
\text { quartzito } 5 \%\end{array}$ & 5 & 8 \\
\hline Intermediário & C & $\begin{array}{c}15-20 / \\
670\end{array}$ & $\begin{array}{l}\text { quartzo } 94 \% \\
\text { itabirito } 6 \%\end{array}$ & 3 & 2,5 \\
\hline Inferior & & $\begin{array}{c}0,2 / \\
695-685\end{array}$ & $\begin{array}{l}\text { quartzo, } \\
\text { itabirito, } \\
\text { quartzito }\end{array}$ & 4 & $\begin{array}{c}\text { Montante da Serra do Curral: } 7 \\
\text { Jusante da Serra do Curral: } 5\end{array}$ \\
\hline Inferior & B & $\begin{array}{l}0,2 / \\
680\end{array}$ & $\begin{array}{l}\text { quartzo, } \\
\text { itabirito, } \\
\text { quartzito }\end{array}$ & 3 & 4 \\
\hline Inferior & $\mathrm{C}$ & $\begin{array}{l}0,2 / \\
665\end{array}$ & quartzo, itabirito & 2 & 4 \\
\hline
\end{tabular}


níveis de terraceamento, ilustradas pela Fig. 8, consistem em bruscos desnivelamentos, coincidentemente localizados nos contatos entre os domínios morfoestruturais regionais. Os dados quantitativos correspondentes (cotas e alturas) encontram-se no Quadro 1.

Com relação às deformações diretas, trata-se de falhamentos deslocando o contato seqüências aluviais/ substrato rochoso, bem como as camadas aluviais.

O melhor exemplo é o do Terraço Intermediário, na área de confluência entre o rio das Velhas e o córrego da Quarta-Feira, no segmento B (Foto 1). O contato gnáisses/aluviões é deslocado por uma falha normal de direção NE-SW e rejeito de $1.5 \mathrm{~m}$. É também nítido o basculamento do terraço em sentido NW.

Ainda no segmento B, nas proximidades do bairro Frimisa, em Santa Luzia (segmento B), os depósitos do mesmo nível de terraço encontram-se excessivamente inclinados, fato associado a inúmeros deslocamentos recentes observados no substrato rochoso.

A ocorrência de uma captura fluvial nas adjacências da vila de Pinhões, no segmento C, tinha sido anteriormente assinalada por A. Saadi (inédito). $\mathrm{O}$ estudo detalhado da área confirmou o fato e permitiu atribuí-lo a um evento cronologicamente posterior à instalação do Terraço Intermediário (Fig. 9).

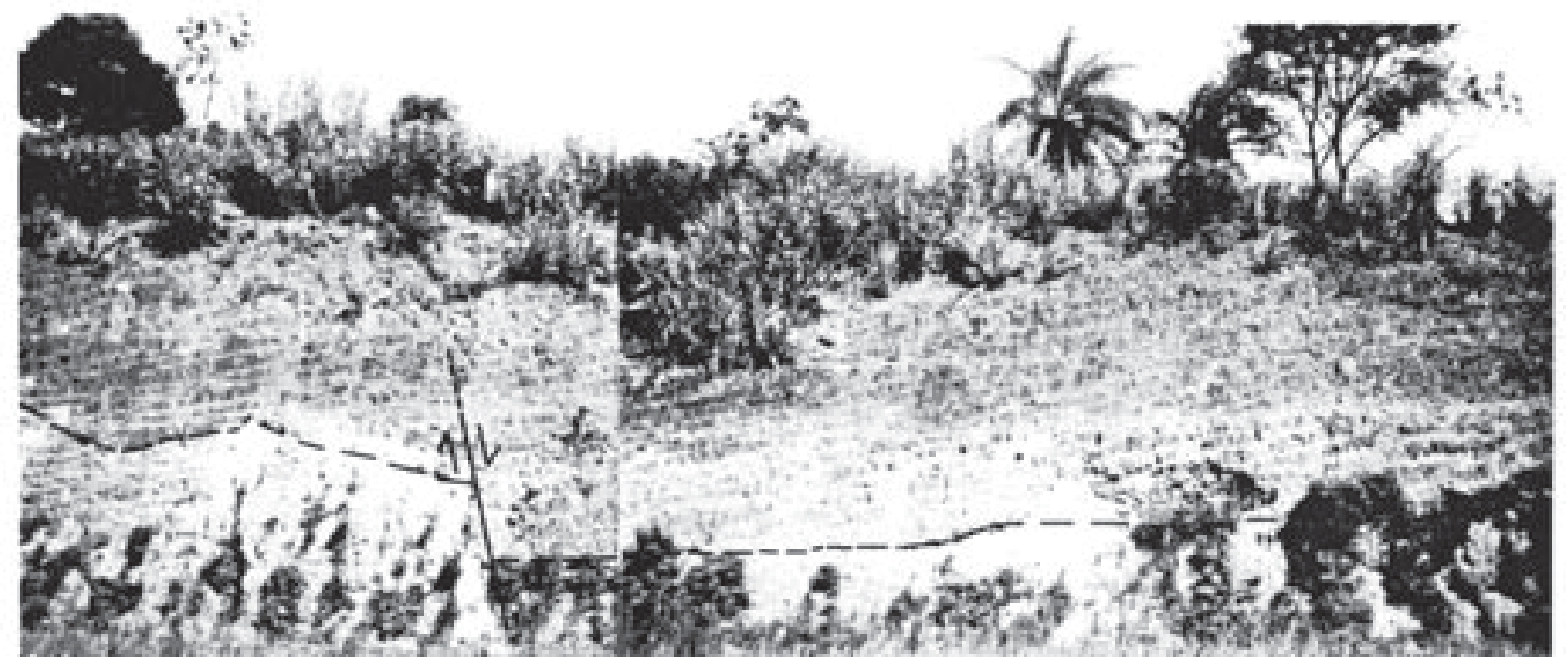

Foto 1:Falha normal no terraço intermediário com rejeito de 1,5 $\mathrm{m}$.

Photo 1: Normal fault in the middle terrace with offset of $1.5 \mathrm{~m}$.

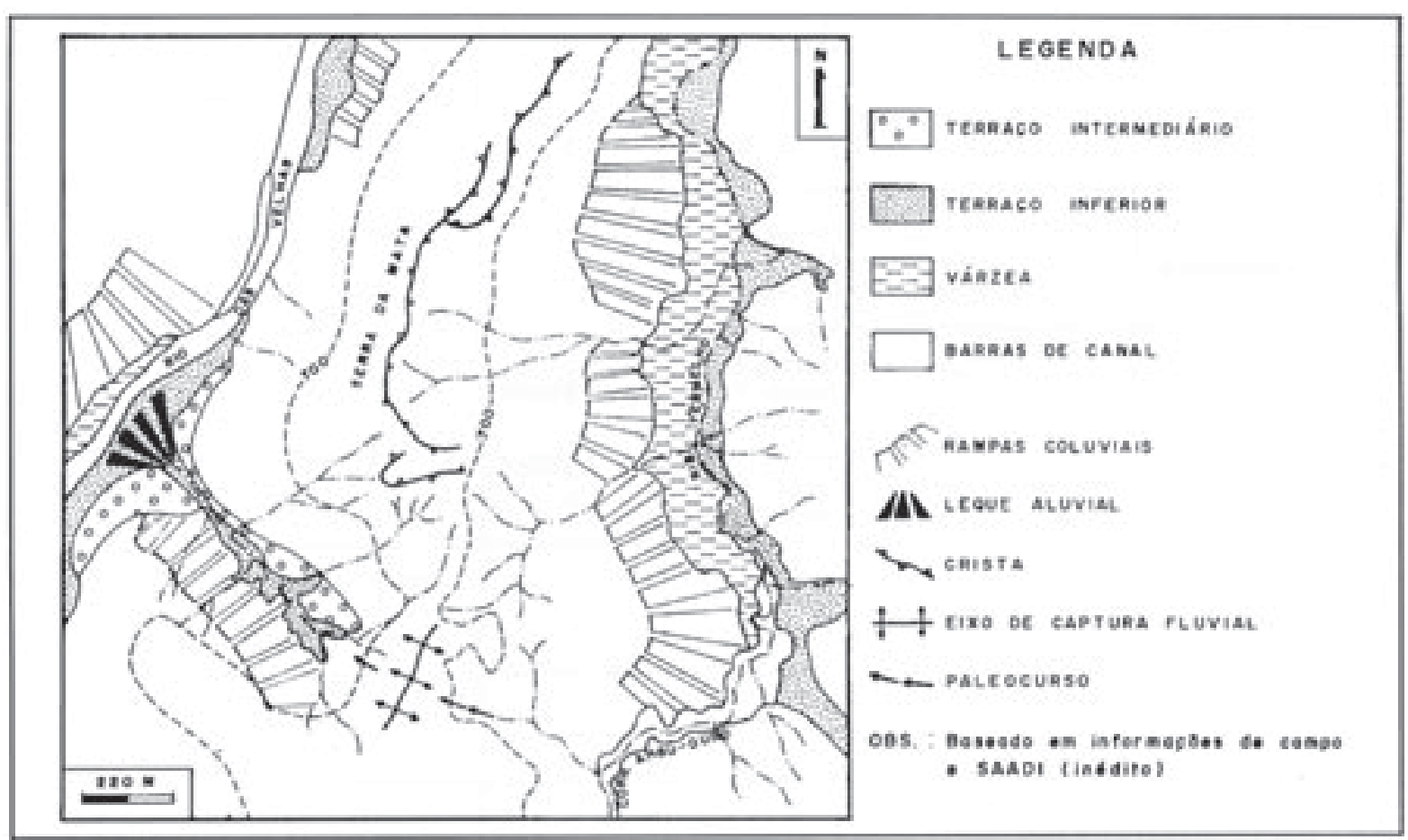

Figura 9: Paleocurso do Córrego Angu-Duro em Pinhões

Figure 9: Paleo channel of Angu-Duro river, near Pinhões. 
$\mathrm{O}$ atual córrego do Angú-Duro devia constituir o curso superior do pequeno curso d' água (s.n.) que drena o vale de Pinhões, desaguando no rio das Velhas na altura da vila. Posteriormente à instalação do Terraço Intermediário, este curso superior foi capturado pelo ribeirão Santo Antônio, que conflui com o rio das Velhas cerca de $1 \mathrm{~km}$ à jusante. Este fato é evidenciado principalmente pela presença de um testemunho de terraço atribuído ao nível Intermediário, encravado no vale de Pinhões, mas apresentando seqüência aluvial incompatível com as características atuais do curso d' água que o drena. De fato, o volume e o avançado grau de arredondamento dos seixos de quartzo implicam em uma distância de transporte muitas vezes maior do que a permitida pelo comprimento atual do vale. Por outro lado, a excessiva largura do vale de Pinhões é incompatível com o seu reduzido comprimento e a pequena vazão permitida pela atual área de drenagem. Finalmente, a posição dos testemunhos deste terraço não permitem associá-lo ao rio das Velhas, pois encontram-se localizados em encostas do vale de Pinhões inatingíveis por este, em qualquer hipótese de paleomeandramento.

A captura é interpretada como conseqüência do abatimento do bloco que contém o curso inferior do ribeirão Vermelho ao longo de uma falha de direção N.NE-S.SW, que controla o escarpamento da Serra da Mata. Deste modo, o escoamento do paleo-rio em direção NW encontrou-se barrado e forçado a lançarse no vale do ribeirão Vermelho.

Confirma esta interpretação o entulhamento aluvial posterior do curso inferior do ribeirão Vermelho, próximo ao Convento dos Macaúbas, enquanto os outros afluentes do rio das Velhas são mais encaixados. Além do mais, deslocamentos de blocos como o previsto, são observados em vários locais da borda da Bacia do Grupo Bambuí, envolvendo pacotes de filitos e calcários.

\section{INTERPRETAÇÃO E DISCUSSÃO DOS RESULTADOS}

A presença de remanescentes de superfícies antigas foi proposta nas serras do Quadrilátero Ferrífero a altitudes de 1.200 a 2.100 m (King 1956, Barbosa \& Rodrigues 1967, Dorr 1969), mas o caráter local dos presumidos testemunhos e as controvérsias que, cada vez mais, lançam dúvidas sobre sua existência (Varajão 1991) não permitem uma retrospectiva confiável.

Apesar disto, parece não haver muitas dúvidas sobre a formação de um extenso nível de aplainamento durante o Terciário, em grande parte da Plataforma Brasileira, denominado por King (1956) de Superfície Sul-Americana. Segundo as propostas deste autor e de Dorr (1967), a origem da referida superfície remonta ao Eoceno-Oligoceno, estando preservada a 850-900 m na região. De fato, esta superfície parece bem marcada na região por uma linha de topos aplainados na Depressão de Belo Horizonte e conectados por rampas suaves à Serra do Curral. Seus depósitos correlativos não são encontrados na área estudada, mas podem ser representados pelas mais altas cascalheiras dos topos de colinas e esporões localizados a norte do Fecho do Funil, em torno do vale do rio Paraopeba.

A análise da sucessão de eventos morfodinâmicos na área, será portanto realizada considerando esta superfície como o marco morfológico/cronológico referencial. Porém, deve-se ressaltar que as investigações efetuadas em grande parte do Estado de Minas Gerais (Saadi 1991), incitam a aceitar uma preservação da Superfície Sul-Americana até meados ou final do Mioceno.

O rebaixamento do nível de base que desencadeou a dissecação desta superfície foi considerado pelo conjunto dos autores como induzido por soerguimentos crustais, acompanhados de basculamento generalizado e desnivelamentos localizados.

O processo de reconstituição paleo-ambiental foi realizado tendo-se em mente que os depósitos que hoje subsistem não representam a completa história morfodinâmica de uma área. Este fato é importante ao analisar-se as descontinuidades deposicionais na paisagem, principalmente quando relacionadas a eventos bastante antigos.

\section{O significado do nível de Terraço Superior}

Conseqüentemente à vaga erosiva que conduziu à dissecação da Superfície Sul-Americana, os vales entalhados até à cota atual de $750 \mathrm{~m}$ sofreram um importante entulhamento, responsável pela deposição dos detritos grosseiros que compõem as seqüências do Terraço Superior. O sistema fluvial apresentava um padrão próximo ao entrelaçado, com predomínio de carga de leito.

Este evento deposicional pode ser relacionado ao ciclo Velhas mais antigo da região, conforme definição de King (1956) e a opinião de Dorr (1967), para quem os ciclos Velhas estariam representados no Quadrilátero Ferrífero, por terraços a altitudes de 700 a $750 \mathrm{~m}$.

Na hipótese de existir uma certa proporcionalidade entre soerguimento e erosão vertical, isto significaria que o alçamento tectônico da região, durante o período em questão, atingiu uma amplitude máxima de 150 metros (entre as atuais cotas de 900 e $750 \mathrm{~m}$ ).

A posição do Terraço Superior na cota 700 m, no meio do segmento $C$, deve ser considerada como resultado de deslocamento posterior, com abatimento de bloco setentrional (vide Fig. 8). Isto explicaria o brusco desnivelamento dos remanescentes do mesmo terraço numa altura de $50 \mathrm{~m}$, gerando um gradiente anómalo de $1.85 \%$ no perfil longitudinal. Porém, a análise do perfil longitudinal do Terraço Intermediário mostrará que este desnivelamento corresponde a uma soma de rejeitos envolvendo dois eventos de deslocamento tectônico.

A ocorrência deste fato no contato entre embasamento arqueano e sedimentos proterozóicos, permite relacioná-lo com a movimentação da borda da 
Bacia do Grupo Bambui, onde são observados falhamentos e flexuras das camadas proterozóicas.

\section{Rebaixamento do nível de base e instalação das seqüências do Terraço Intermediário}

Posterioremente à instalação das seqüências do Terraço Superior, um novo rebaixamento do nível de base comanda uma segunda fase de dissecação, com profundidade aparentemente variável ao longo do vale: 40-50 m no segmento A, 60-70 m no segmento B e 80 $\mathrm{m}$ no segmento $\mathrm{C}$, calculados com base nas diferenças de cotas entre os respectivos testemunhos dos terraços Superior e Intermediário (Fig. 8).

No entanto, a ocorrência de dois tipos de anomalias no perfil longitudinal induz a busca de interpretação mais pormenorizada:

a- bruscos desnivelamentos entre testemunhos do terraço, gerando gradientes de $0.6 \%$ (contato dos segmentos A e B) e $0.83 \%$ (contato dos segmentos $\mathrm{B}$ e C);

b- posição sobre-elevada de dois testemunhos, na área de transição entre os segmentos B e C, com relação aos testemunhos localizados a montante.

Estas anomalias, associadas aos deslocamentos tectônicos observados diretamente nos testemunhos do Terraço Intermediário (Foto 1), conduzem a admitir que esta configuração não corresponde à do perfil longitudinal original deste nível de terraceamento. A intervenção posterior de falhamentos localizados fazse necessária, rebaixando a porção central do segmento $\mathrm{B}$ e, novamente, a porção setentrional do segmento C.

A projeção de um perfil longitudinal sem deformação situaria o Terraço Intermediário na cota aproximada de $680 \mathrm{~m}$, na extremidade norte. Com base nisto, pode-se estimar um rejeito tectônico de 10 metros para este evento. Conseqüentemente, o rejeito do $1^{\circ}$ evento que deslocou o Terraço Superior, seria de aproximadamente 40 metros. O brusco desnivelamento de 50 metros, atualmente observado entre testemunhos deste terraço, é o resultado da somatória dos rejeitos dos dois eventos.

As seqüências do Terraço Intermediário foram geradas sob condições semelhantes às do Terraço Superior, resultando igualmente em um padrão de canal de tipo próximo ao entrelaçado. A ausência de um padrão entrelaçado clássico foi confirmada pela reconstituição de paleo-meandramentos contemporâneos da sedimentação. Estes foram reconstituidos através da identificação de bordas de paleo-meandros nas encostas do vale e de direções de paleocorrentes (vide Fig.5)

Variações longitudinais nas características das seqüências aluviais do Terraço Intermediário, tais como espessura das seqüências, comprimento e petrografia dos seixos (vide Quadro 1), forneceram elementos complementares para a identificação de uma importante mudança no comportamento da evolução morfogenética, posteriormente à formação do Terraço Superior. a- a espessura do pacote aluvionar varia de $40 \mathrm{~m}$, a montante do Fecho de Sabará, para $10 \mathrm{~m}$ logo a jusante, $8 \mathrm{~m}$ no segmento $\mathrm{B}$ e $2.5 \mathrm{~m}$ no $\mathrm{C}$;

b- o comprimento médio dos seixos varia de $6 \mathrm{~cm}$, no segmento A, para $5 \mathrm{~cm}$, no B e $3 \mathrm{~cm}$, no $\mathrm{C}$;

c- a petrográfica dos seixos sofre importante homogeneização de montante para jusante, passando da composição "itabirito=49 \%, quartzo $=41 \%$, quartzito $=10 \%$ " para a composição "quartzo $=94 \%$, itabirito $=6 \% "$.

Estes dados indicam que a Serra do Curral atuou, neste momento, como barreira ao escoamento dos sedimentos, induzindo um acentuado entulhamento do vale a montante do Fecho de Sabará. Com a ausência do represamento à jusante da serra, a carga sedimentar pôde ser melhor mobilizada, resultando na rápida redução das espessuras. A diminuição do tamanho dos seixos e a homogeneização petrográfica, demonstram que o desgaste erosivo processou-se dentro dos limites do trecho estudado.

Comparando estas características com as do Terraço Superior, observa-se que durante a instalação de suas seqüências não ocorria o efeito de barramento. Isto é demonstrado tanto pela regularidade das espessuras ( 5 m) mesmo que residuais, quanto pela homogeneização petrográfica realizada já a montante da Serra do Curral, que indicam um perfil longitudinal regularizado neste trecho.

Fica portanto claro que no intervalo decorrido entre a deposição das duas seqüências aluviais, devem ter ocorrido drásticas mudanças na morfologia do vale do rio das Velhas. O deslocamento tectônico com rejeito de $40 \mathrm{~m}$, observado no nível de Terraço Superior, sugere que tais mudanças possuem origem tectônica.

Por fim, considerando um perfil longitudinal original deste terraceamento depurado dos efeitos de falhamentos (realizado entre as cotas $710 \mathrm{~m}$, a montante e $680 \mathrm{~m}$, a jusante), avaliou-se, para o correspondente evento erosivo, uma profundidade de dissecação variando entre $50 \mathrm{~m}$, a montante e $70 \mathrm{~m}$, a jusante. Isto indicaria uma altura média de soerguimento próxima de 60 metros.

\section{A Nova Fase de Rebaixamento do Nível de Base e o Nível de Terraço Inferior}

A deposição das seqüências aluviais do Terraço Inferior foi efetuada após uma dissecação que atingiu profundidaes de $10 \mathrm{~m}$, a montante e $15 \mathrm{~m}$, a jusante. Esta gerou um entulhamento generalizado do vale, através de canal de tipo também próximo ao entrelaçado.

O entulhamento foi, igualmente ao período anterior, mais intenso à montante da Serra do Curral onde atinge espessura de $7 \mathrm{~m}$, reduzida a jusante para $5 \mathrm{~m}$. Nos segmentos B e C, a espessura estabiliza-se em $4 \mathrm{~m}$. Desta forma, a Serra do Curral continuou represando o fluxo sedimentar, condicionando o referido padrão tipo braided.

A redução esperada da espessura no segmento $\mathrm{C}$ 
foi, em parte, compensada por aportes sedimentares de inúmeros leques aluviais oriundos de afluentes locais. Estes aportes são representados por lençóis de seixos de quartzo angulosos a sub-arredondados, interdigitados com as camadas de origem mais longínqua. Neste nível verificou-se também a realização da homogeneização petrográfica a partir do Fecho de Sabará (vide Quadro 1).

O papel da atividade tectônica no rebaixamento do nível de base é evidenciado, neste caso, por: escalonamento de 10-15 m com relação ao Terraço Intermediário, deslocamentos do mesmo por falhas nas zonas de contato entre compartimentos morfoestruturais e, em especial, captura do córrego do Angú-Duro pelo ribeirão Vermelho.

\section{O Nível de Várzea e a Dinâmica Deposicional Atual}

A tendência à atenuação gradual dos efeitos do soerguimento parece se confirmar com o embutimento dos sedimentos da Várzea nas seqüências do Terraço Inferior.

O fato novo é representado por mudanças na dinâmica deposicional, sendo a Várzea caracterizada por três fases sedimentares relacionadas a um padrão de tipo próximo ao meandrante, inclusive com ocorrências de depósitos orgânicos.

A gradual redução na presença de finos da primeira à terceira fases deposicionais da Várzea, marca o início da mudança no padrão sedimentar do rio das Velhas, fato que se acentua com a dinâmica sedimentar atual, em que praticamente não são depositados finos no trecho de vale estudado. O elevado afluxo sedimentar atual, além da mudança no tipo de carga, é também responsável pela formação de inúmeras barras de canal, fazendo-se prever a gradual transformação do sistema, novamente em direção a um padrão mais próximo ao entrelaçado.

Datações absolutas (método do radiocarbono) realizadas por Kohler (1989) nas seqüências da Várzea, em trecho do rio das Velhas próximo a Lagoa Santa, conferem à base da mesma idade de 13.000 a 22.000 BP. Em camadas interpretadas como correspondentes ao topo da $2^{\text {a }}$ fase, o mesmo autor obteve idades de $5.150 \pm 300$ e $3.060 \pm 220 \mathrm{BP}$.

No que diz respeito à $3^{\mathrm{a}}$ fase, a acentuação do caráter braided, na região de Belo Horizonte, está claramente associada à influência antrópica, principalmente através das atividades da mineração (manual e mecanizada) efetuada a montante, não só no leito atual como nos terraços.

A mudança no padrão de canais fluviais durante os últimos séculos, vem sendo verificada em vales de várias partes do mundo (Werrity \& Ferguson 1980, Macklin et al. 1992), apontando conseqüências drásticas das atividades antrópicas sobre os processos de erosão e transporte de sedimentos.

\section{CONCLUSÃO}

A análise da dinâmica fluvial do rio das Velhas na zona de contato entre o Quadrilátero Ferrífero e a Depressão de Belo Horizonte, mostra que a evolução morfogenética da região foi caracterizada por duas fases distintas.

A primeira, situada no Terciário, é representada por testemunhos de eventos erosivos relacionados com a Superfície Sul-Americana e o $1^{\circ}$ Ciclo Velhas de King (1956). Estes são caracterizados, na referida zona de contato, por perfís longitudinais regularizados. O alinhamento de itabiritos da Serra do Curral parece não ter oferecido uma resistência notável à ação dos cursos d'água, permitindo o alargamento do vale e, conseqüentemente o livre trânsito da carga sedimentar.

Do ponto de vista cronológico, a deposição das cascalheiras do Terraço Superior deve encerrar o período pliocênico.

Durante o Pleistoceno, a sedimentação aluvial a jusante do Quadrilátero Ferrífero é controlada pela Serra do Curral, que atua com barreira eficiente, através do Fecho de Sabará.

Os compartimentos morfoestruturais firmados pelos efeitos antagônicos do soerguimento e da morfogênese, diferenciada em função da resistência litológica, influenciam a morfologia do vale e assumem os papéis de zonas proximal (Quadrilátero Ferrífero), intermediária (Depressão de Belo Horizonte) e distal (Bacia do Bambui).

A morfogênese processa-se em regime de instabilidade crustal permanente, apenas diferenciada no tempo por variações de intensidade. O escalonamento dos níveis de terraços em todos os compartimentos demonstra a permanente ocorrência de um soerguimento crustal de alcance regional. Os deslocamentos por falhas localizados preferencialmente nos limites desses compartimentos, assinalam a mobilidade das zonas de contato entre unidades litoestruturais précambrianas. Esta mobilidade pode ser interpretada como conseqüência do processo de soerguimento, mas também como resultado de esforços tectônicos independentes deste. Neste caso, deve-se pensar na contribuição de esforços tectônicos relacionados com a deriva da Placa Sul-Americana em direção geral W-NW (Hasui 1990), da qual resultam campos de tensões com eixo de compressão máxima de direção média NW-SE para o Estado de Minas Gerais (Saadi 1991, 1993).

\section{AGRADECIMENTOS}

As pesquisas que permitiram a realização deste trabalho foram desenvolvidas graças ao apoio financeiro da Pró-Reitoria de Pesquisa da UFMG, ao apoio do $\mathrm{CNPq}$ (bolsa de pesquisa). Estas pesquisas foram realizadas no quadro do Projeto CAPES- 
COFECUB ( $\mathrm{n}^{\circ}$ 125/91), tendo o Prof. Henri Vogt (ULP-Strasbourg, França) oferecido valiosas sugestões na ocasião de um trabalho de campo na área.

Os autores agradecem ainda os colegas Antônio Wilson Romano pela leitura crítica e proveitosa do texto, Friedrich E. Renger pela confecção do abstract.

\section{REFERÊNCIAS BIBLIOGRÁFICAS}

ALKMIM, F.F.; CHEMALE Jr., F.; BACELAR, L.A.P.; OLIVEIRA, J.R.P. \& MAGALHÃES, P.M.1989. Arcabouço estrutural da Porção Sul da Bacia do São Francisco. In: SIMPÓSIO DE GEOLOGIA DE MINAS GERAIS, 5 SIMPÓSIO DE GEOLOGIA NÚCLEO BRASÍLIA, 1, 1989, Belo Horizonte. Anais... Belo Horizonte, SBG-MG, 1989. Bol. $\mathrm{n}^{\circ}$ 10: 289- 292.

BARBOSA, G.V. \& RODRIGUES, D.M.S. 1967. Quadrilátero Ferrifero. Belo Horizonte, IGC-UFMG, Imprensa Universitária.

BARBOSA, G.V. 1980. Superfícies de erosão no Quadrilátero Ferrífero - Minas Gerais. Rev. Bras. Geoc.,.10(1):89-101.

COSTA, M.T. da. \& SAD, J.H.G. 1987. A Série Bambuí em Minas Gerais. In: SIMPÓSIO DE GEOLOGIA DE MINAS GERAIS, 4, 1987, Belo Horizonte. Anais...Belo Horizonte, SBG-MG, 1987. Bol. $\mathrm{n}^{\circ}$ 7: 1-9.

COUTO, J.G.P.; TEIXEIRA, W. \& CORDANI, U.G. 1983. Considerações sobre as principais épocas de fraturamento do Cráton do São Francisco, com base em datações K-Ar em rochas básicas. In: SIMPÓSIO DE GEOLOGIA DE MINAS GERAIS, 2, 1983, Belo Horizonte. Anais... Belo Horizonte, SBG-MG, 1983. Bol. $\mathrm{n}^{\circ}: 38-49$.

DARDENNE, M.A. 1978. Síntese sobre a estratigrafia do Grupo Bambuí no Brasil Central. In: CONGRESSO BRASILEIRO DE GEOLOGIA, 30, 1978, Recife. Anais... Recife, SBGNúcleo Nordeste, 1978. 2: 597- 610.

DORR, J.V.N. 1967. Desenvolvimento fisiográfico, estratigráfico e estrutural do Quadrilátero Ferrifero, Minas Gerais, Brazil. Geologia Regional do Quadrilátero Ferrífero, Minas Gerais, Brasil. Washington: U.S. Government Printing Office, 1967.

GORCEIX, H. 1884. Bacias terciárias de d' água doce nos arredores de Ouro Preto (Gandarela e Fonseca), Minas gerais, Brazil. Anais da Escola de Minas de Ouro Preto, 3:75-92.

GUILD, P. W. 1960. Geologia e Recursos Minerais do Distrito de Congonhas, Estado de Minas Gerais. Trad. Aluizio L.M.B., Rio de Janeiro: Ministério da Agricultura - DNPM, 1960.
HASUI, Y. 1990. Neotectônica e aspectos fundamentais da tectônica ressurgente no Brasil. In: WORKSHOP S/NEOTECTÔ. E SEDIM. CENOZ. CONT. NO SE BRASIL., 1, 1990, Belo Horizonte. Anais...Belo Horizonte, SBG/MG, 1992. Bol. n 11: $1-31$.

KING, L.C. 1956. Geomorfologia do Brasil Oriental. Rev. Bras. Geog., 18(2): 147-266.

KOHLER, H.C. 1989. Geomorfologia cárstica da região de Lagoa Santa-MG. São Paulo, USP. 1989, tese de Doutoramento. 113 p.

LADEIRA, E.A. 1980. Metallogenesis of gold at the Morro Velho Mine and in the Nova Lima District, Quadrilatero Ferrifero, Minas Gerais, Brazil. London, Faculty of Graduate Studies, 1980. Tese de doutorado, The University of Western Ontario, $272 \mathrm{p}$.

MACKLIN, M.G.; RUMSBY, B.T. \& HEAP, T. 1992. Flood alluviation and entrenchment: Holocene valley-floor development and transformation in the British Uplands. Geol. Soc. Am. Bull., 104: 631-643.

MAGALHÃES Jr., A.P. \& SAADI, A. 1993. Influências Morfoestruturais e Tectônicas na Dinâmica Fluvial do Rio das Velhas na Região de Belo Horizonte - MG. In: SIMPÓSIO DE GEOGRAFIA FÍSICA APLICADA, 5, 1993. São Paulo. Anais... São Paulo, USP, 1994, p. 55-60.

MOORE, S.L. 1969. Geology and ore deposits of the Antônio dos Santos, Gongo Soco and Conceição do Rio Acima quadrangles, Minas Gerais, Brazil. Geological Survey Professional Paper, Washington, 341-I.

SAADI, A. 1991. Ensaio Sobre a Morfotectônica de Minas Gerais. Belo Horizonte, IGC/UFMG, março de 1991 (Tese para provimento de cargo de Professor Titular). $285 \mathrm{p}$.

SAADI, A. 1993. Neotectônica da Plataforma Brasileira: esboço e interpretação preliminares. Geonomos, 1(1): 1-15.

SAADI, A.; SGARBI, G.N.C. \& ROSIERE, C.A. 1992. A Bacia do Gongo Soco; uma nova bacia terciária no Quadrilátero Ferrífero; controle cárstico e/ou tectônico. In:CONG. BRAS. GEOL., 37, 1992, São Paulo. Anais... São Paulo, SBG, 1992, vol. 1:600601.

VARAJÃO, C.A.C. 1991. A questão da correlação das superfícies de erosão do Quadrilátero Ferrífero, Minas Gerais. Rev. Bras. Geoc., 21(2): 138-145.

WERRITTY, A. \& FERGUSON, R.I. 1980. Pattern changes in a scottish braided river over 1,30 and 200 years. In: CULLINGFORD, R.A.; DAVIDSON, D.A. \& LEWIN, J. (edits.). Timescale in geomorphology. Chichester: John Wiley \& Sons, 1980. 